\title{
Toxin-centric development approach for next-generation antivenoms
}

\section{Laustsen, Andreas H.}

Published in:

Toxicon

Link to article, DOI:

10.1016/j.toxicon.2018.05.021

Publication date:

2018

Document Version

Peer reviewed version

Link back to DTU Orbit

Citation (APA):

Laustsen, A. H. (2018). Toxin-centric development approach for next-generation antivenoms. Toxicon, 150, 195197. https://doi.org/10.1016/j.toxicon.2018.05.021

\section{General rights}

Copyright and moral rights for the publications made accessible in the public portal are retained by the authors and/or other copyright owners and it is a condition of accessing publications that users recognise and abide by the legal requirements associated with these rights.

- Users may download and print one copy of any publication from the public portal for the purpose of private study or research.

- You may not further distribute the material or use it for any profit-making activity or commercial gain

- You may freely distribute the URL identifying the publication in the public portal

If you believe that this document breaches copyright please contact us providing details, and we will remove access to the work immediately and investigate your claim 


\section{Accepted Manuscript}

Toxin-centric development approach for next-generation antivenoms

Andreas H. Laustsen

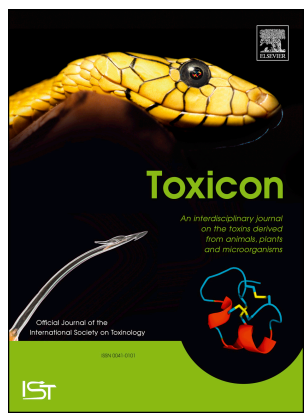

PII: $\quad$ S0041-0101(18)30210-1

DOI: $\quad$ 10.1016/j.toxicon.2018.05.021

Reference: TOXCON 5902

To appear in: Toxicon

Received Date: 19 April 2018

Revised Date: 17 May 2018

Accepted Date: 28 May 2018

Please cite this article as: Laustsen, A.H., Toxin-centric development approach for next-generation antivenoms, Toxicon (2018), doi: 10.1016/j.toxicon.2018.05.021.

This is a PDF file of an unedited manuscript that has been accepted for publication. As a service to our customers we are providing this early version of the manuscript. The manuscript will undergo copyediting, typesetting, and review of the resulting proof before it is published in its final form. Please note that during the production process errors may be discovered which could affect the content, and all legal disclaimers that apply to the journal pertain. 
2 Toxin-centric development approach for next-generation antivenoms

4 With its recent re-introduction on the World Health Organization's list of Neglected Tropical

5 Diseases (Chippaux, 2017), snakebite envenoming is gaining increased international attention. Not

6 only does this create hope that new policies and guidelines may help healthcare systems to 7 implement better preventive strategies, but it may also create incentive for research and development efforts aiming at delivering new antivenom products for treatment of snakebite envenoming. New products may fall into two categories: 1) Plasma-derived antivenoms based on

10 conventional immunization approaches (Gutiérrez et al., 2011; World Health Organisation, 2010)

11 and 2) next-generation antivenoms based on specific therapeutic molecules that are selected on their 12 ability to neutralize key toxins (Knudsen and Laustsen, 2018), and which are manufactured without

13 the need to procure snake venoms. The benefit of the first type of antivenom products is that their 14 therapeutic benefits have been historically documented (Gutiérrez et al., 2011). However, they 15 suffer from the drawback of not being compatible with the human immune system due to their 16 heterologous nature (Laustsen et al., 2016a), and from having a low content of therapeutically active antibodies, particularly against small venom components with low immunogenicity and high toxicity (Laustsen et al., 2017; Leong et al., 2015; Tan et al., 2015, 2016). In recent time, venomics

19 and antivenomics approaches have helped build a greater understanding of the antigenicity of 20 different venom components, which may provide guidance on how to design immunization 21 mixtures that give rise to venom-paraspecific antibody responses in production animals (Calvete et 22 al., 2014, 2009; Lomonte and Calvete, 2017). Such knowledge creates a foundation for improving 23 the neutralization potential of antivenoms against toxin subfamilies with low immunogenicity, such 
as small neurotoxins from the three-finger toxin family (Calvete et al., 2018; Tan et al., 2017). In contrast to plasma-derived antivenoms, the development of next-generation antivenoms is unaffected by any discrepancy between toxicity and immunogenicity, as monoclonal antibodies and small molecule inhibitors can be discovered even for non-immunogenic toxins.

Independent on the particular molecular scaffold (small molecule, antibody, antibody fragment etc.) employed in a next-generation antivenom, a fundamental change in our understanding of snake venoms as drug targets will have to occur. Conventional antivenom manufacture involves the use of whole venoms during the immunization process. For this approach, it is important to optimize the immunization mixture to ensure that the venoms employed are representative of the venoms in the geographic region the antivenom is to be deployed (Gutiérrez, 2007). This necessitates the collection of snakes with venom compositions that are representative of the given region, as such venom compositions have been shown to vary quite dramatically across geographic ranges (Chippaux et al., 1991). Among other things, this possibly creates an incentive for establishing serpentaria in different regions of the world.

$$
\text { In contrast to conventional antivenom manufacture, the manufacture of next- }
$$
generation antivenoms installs a very different demand, as these antivenoms are not dependent on snake venoms for their manufacture (Laustsen et al., 2016b). A thorough understanding of venom compositions in relation to geographic region is still essential to guide the compositional formulation of next-generation antivenoms (Laustsen, In press), but the need to procure snake venoms in large quantities becomes irrelevant. In fact, the development of specific molecular antitoxins is not even reliant on 'representative' whole venoms, if the key toxins can be isolated from a given venom in sufficient quantities for antitoxin discovery purposes (Figure 1). 


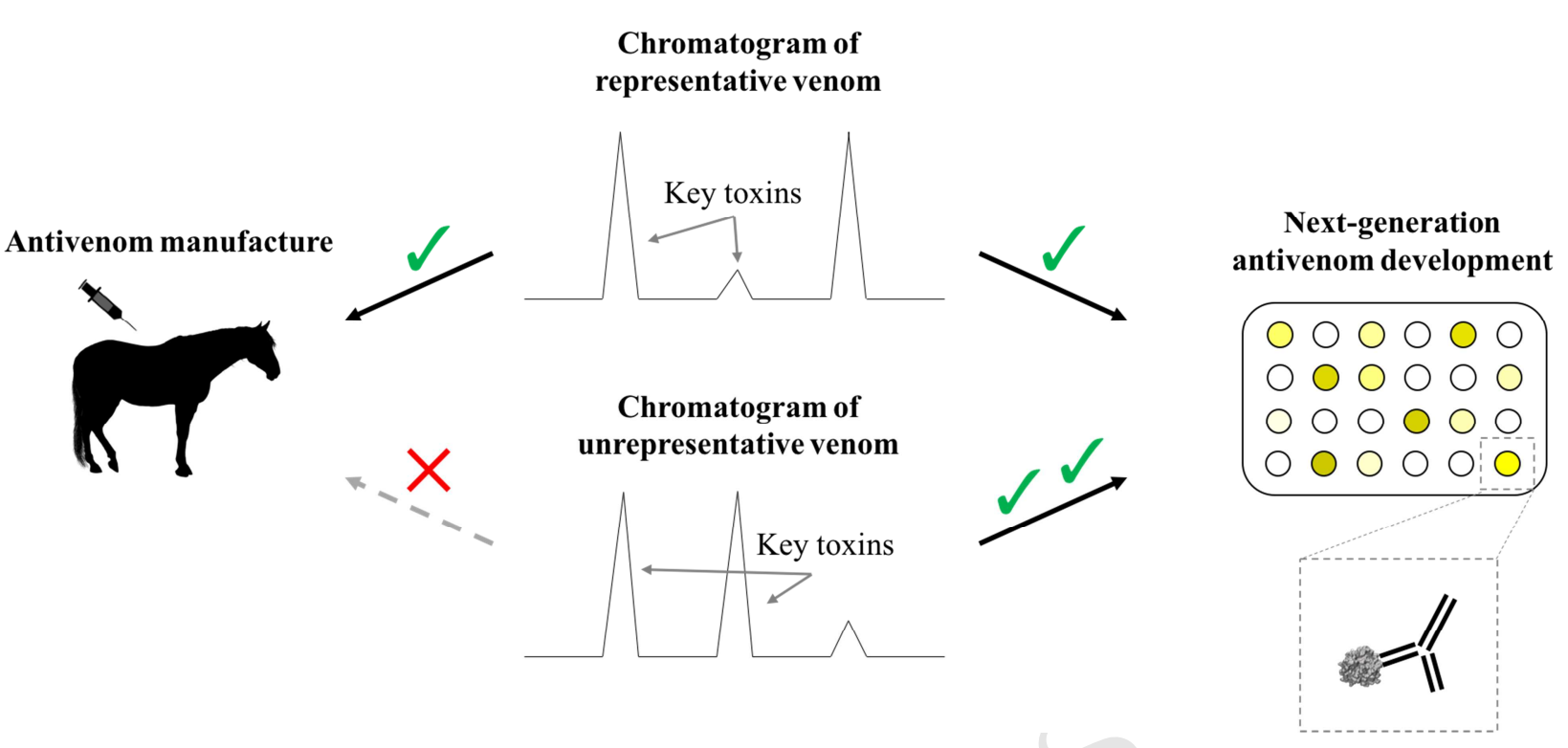

Figure 1. Schematic representation of chromatograms for two different venoms from the same snake species (one venom that is representative of the venom compositions of snakes in a given geographic region and one venom that is not). For antivenom manufacture, it is important that the venoms employed in the immunization mixture are representative of the venoms in the geographic region that the antivenom is to be deployed. In comparison, a venom does not need to be representative when used for next-generation antivenom development purposes, as the key toxins typically are to be isolated and used in pure form. An unrepresentative venom with high proportions of key toxins will even be more useful than a representative venom with lower proportions. is unknown. However, the transition from plasma-derived antivenoms to antivenoms based on defined mixtures of synthetic and/or recombinant components seems unlikely not to happen in the

61 future (Laustsen et al., 2016a). With this transition, the need remains for studying snake venom 62 compositions and identifying all toxins that are medically relevant to neutralize (Lomonte and 63 Calvete, 2017), but the focus in antivenom development will indeed change from obtainment of 
64 whole venoms that are representative of certain habitats, age groups, and geographical regions to a more toxin-centric focus, where it is more important to obtain key snake toxins in isolated form than it is to procure representative venoms. With the toxin-centric focus in antivenom development, antitoxin discovery efforts should not aim to identify molecular antitoxins that can target a group of toxins within only one whole venom, but rather focus on neutralization of toxin subfamilies across multiple species and identification of which (conserved) toxin epitopes should be targeted (Engmark et al., 2016, 2017b; Laustsen, In press). This will allow for a mix-and-match approach, where polyvalent next-generation antivenoms can be built up by mixing individual toxin subfamilyspecific antitoxins that combined may neutralize all the key toxin subfamilies in several target venoms (Figure 2). It may therefore become more relevant to identify key toxins from different toxin subfamilies that are essential to be neutralized than to identify whole venoms that are representative for a given species (in a given geographic region). In this context, it may also be relevant to explore how broad target specificity can be obtained for different antitoxins, as it will likely be difficult to identify single antitoxins that can cross-neutralize an entire subfamily of toxins (Engmark et al., 2017a), although promising results have been reported for certain inhibitors against enzymatic toxins (Arias et al., 2017; Knudsen and Laustsen, 2018; Lewin et al., 2016). 


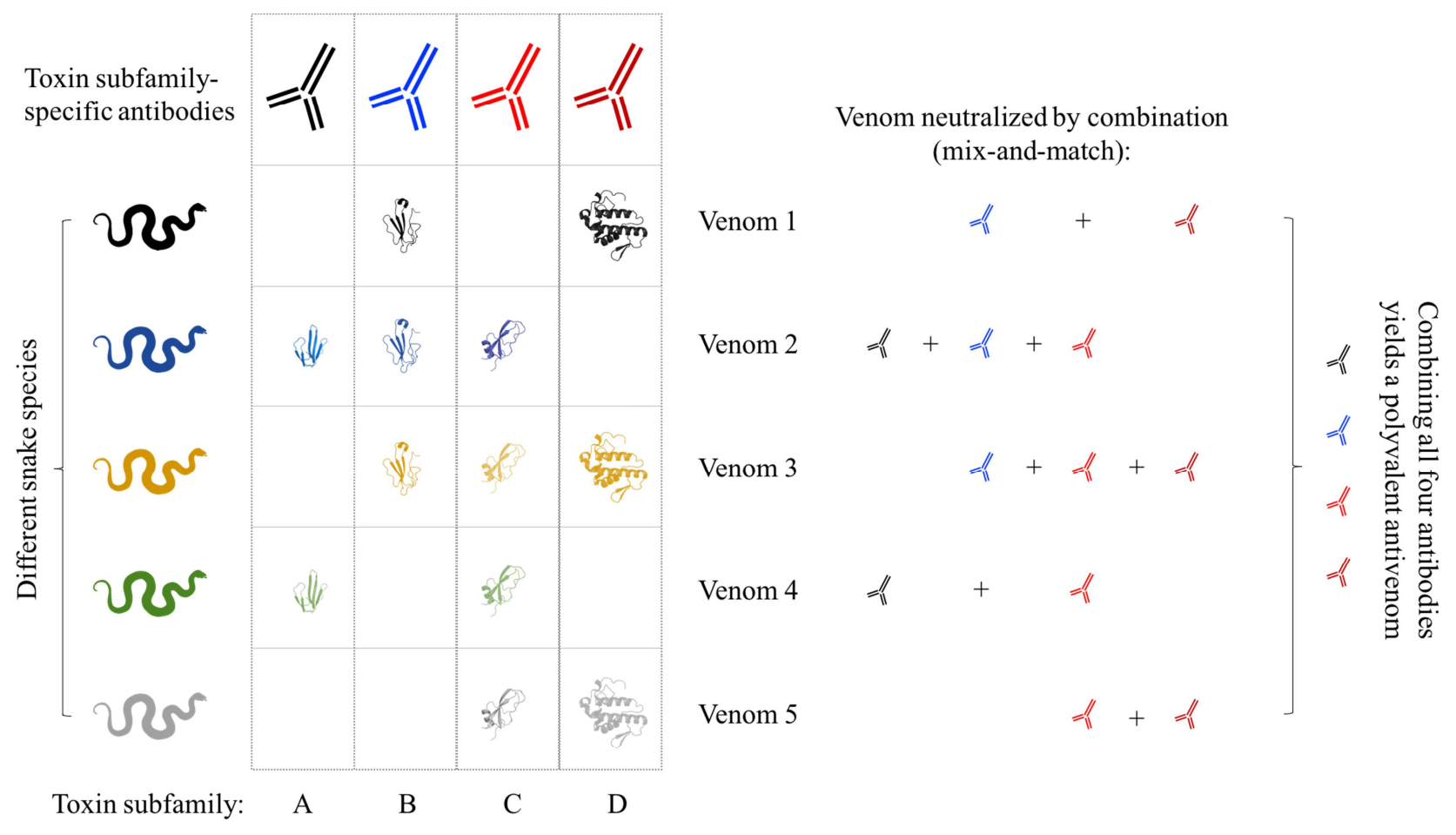

Figure 2: Schematic overview of how polyvalent next-generation antivenoms can be designed by

combining antitoxins (illustrated with IgG antibodies) that can cross-neutralize toxins from the same subfamily across different snake species. This approach requires that focus in antivenom development is shifted from representative whole venoms from specific snake species to becoming more toxin-centric.

If these predictions hold true, the implications may firstly become significant for governments and healthcare systems that are considering the establishment of new serpentaria to obtain collections of snake specimens with venom compositions that are representative for their geographical region, as such serpentaria risk becoming redundant. Secondly, antivenom researchers may have to re-evaluate how they understand the interplay between toxins and venoms and switch from a currently strong focus on neutralizing whole venoms towards a focus on neutralization of toxin subfamilies across multiple snake species. 
Department of Biotechnology and Biomedicine 
102

103

104

105

106

107

108

109

110

111

112

113

114

115

116

117

118

119

120

121

122

123

124

125

126

127

128

129

130

131

132

133

134

135

136

137

138

139

140

141

142

143

144

145

Arias, A.S., Rucavado, A., Gutiérrez, J.M., 2017. Peptidomimetic hydroxamate metalloproteinase inhibitors abrogate local and systemic toxicity induced by Echis ocellatus (saw-scaled) snake venom. Toxicon Off. J. Int. Soc. Toxinology 132, 40-49. https://doi.org/10.1016/j.toxicon.2017.04.001

Calvete, J.J., Rodríguez, Y., Quesada-Bernat, S., Pla, D., 2018. Toxin-resolved antivenomicsguided assessment of the immunorecognition landscape of antivenoms. Toxicon 148, 107122. https://doi.org/10.1016/j.toxicon.2018.04.015

Calvete, J.J., Sanz, L., Angulo, Y., Lomonte, B., Gutiérrez, J.M., 2009. Venoms, venomics, antivenomics. FEBS Lett., Prague Special Issue: Functional Genomics and Proteomics 583, 1736-1743. https://doi.org/10.1016/j.febslet.2009.03.029

Calvete, J.J., Sanz, L., Pla, D., Lomonte, B., Gutiérrez, J.M., 2014. Omics Meets Biology: Application to the Design and Preclinical Assessment of Antivenoms. Toxins 6, 3388-3405. https://doi.org/10.3390/toxins6123388

Chippaux, J.-P., 2017. Snakebite envenomation turns again into a neglected tropical disease! J. Venom. Anim. Toxins Trop. Dis. 23. https://doi.org/10.1186/s40409-017-0127-6

Chippaux, J.P., Williams, V., White, J., 1991. Snake venom variability: methods of study, results and interpretation. Toxicon 29, 1279-1303.

Engmark, M., Andersen, M.R., Laustsen, A.H., Patel, J., Sullivan, E., Masi, F. de, Hansen, C.S., Kringelum, J.V., Lomonte, B., Gutiérrez, J.M., Lund, O., 2016. High-throughput immunoprofiling of mamba (Dendroaspis) venom toxin epitopes using high-density peptide microarrays. Sci. Rep. 6, 36629. https://doi.org/10.1038/srep36629

Engmark, M., Jespersen, M.C., Lomonte, B., Lund, O., Laustsen, A.H., 2017a. High-density peptide microarray exploration of the antibody response in a rabbit immunized with a neurotoxic venom fraction. Toxicon 138, 151-158. https://doi.org/10.1016/j.toxicon.2017.08.028

Engmark, M., Lomonte, B., Gutiérrez, J.M., Laustsen, A.H., De Masi, F., Andersen, M.R., Lund, O., 2017b. Cross-recognition of a pit viper (Crotalinae) polyspecific antivenom explored through high-density peptide microarray epitope mapping. PLoS Negl. Trop. Dis. 11, e0005768. https://doi.org/10.1371/journal.pntd.0005768

Gutiérrez, J.M., 2007. Trends in snakebite envenomation therapy: Scientific, technological and public health considerations. Curr. Pharm. Des. 13, 2935-2950.

Gutiérrez, J.M., León, G., Lomonte, B., Angulo, Y., 2011. Antivenoms for snakebite envenomings. Inflamm. Allergy Drug Targets 10, 369-380.

Knudsen, C., Laustsen, A.H., 2018. Recent Advances in Next Generation Snakebite Antivenoms. Trop. Med. Infect. Dis. 3, 42.

Laustsen, A.H., In press. Guiding recombinant antivenom development by omics technologies. New Biotechnol. https://doi.org/10.1016/j.nbt.2017.05.005

Laustsen, A.H., Engmark, M., Clouser, C., Timberlake, S., Vigneault, F., Gutiérrez, J.M., Lomonte, B., 2017. Exploration of immunoglobulin transcriptomes from mice immunized with threefinger toxins and phospholipases $\mathrm{A}_{2}$ from the Central American coral snake, Micrurus nigrocinctus. PeerJ 5, e2924. https://doi.org/10.7717/peerj.2924

Laustsen, A.H., Engmark, M., Milbo, C., Johannesen, J., Lomonte, B., Gutiérrez, J.M., Lohse, B., 2016a. From Fangs to Pharmacology: The Future of Snakebite Envenoming Therapy. Curr. Pharm. Des. 22, 5270-5293. https://doi.org/10.2174/1381612822666160623073438 
Laustsen, A.H., Solà, M., Jappe, E.C., Oscoz, S., Lauridsen, L.P., Engmark, M., 2016 b. Biotechnological Trends in Spider and Scorpion Antivenom Development. Toxins 8. https://doi.org/10.3390/toxins8080226

Leong, P.K., Fung, S.Y., Tan, C.H., Sim, S.M., Tan, N.H., 2015. Immunological cross-reactivity and neutralization of the principal toxins of Naja sumatrana and related cobra venoms by a Thai polyvalent antivenom (Neuro Polyvalent Snake Antivenom). Acta Trop. 149, 86-93. https://doi.org/10.1016/j.actatropica.2015.05.020

Lewin, M., Samuel, S., Merkel, J., Bickler, P., 2016. Varespladib (LY315920) Appears to Be a Potent, Broad-Spectrum, Inhibitor of Snake Venom Phospholipase $\mathrm{A}_{2}$ and a Possible PreReferral Treatment for Envenomation. Toxins 8. https://doi.org/10.3390/toxins8090248

Lomonte, B., Calvete, J.J., 2017. Strategies in 'snake venomics' aiming at an integrative view of compositional, functional, and immunological characteristics of venoms. J. Venom. Anim. Toxins Trop. Dis. 23. https://doi.org/10.1186/s40409-017-0117-8

Tan, C.H., Tan, K.Y., Lim, S.E., Tan, N.H., 2015. Venomics of the beaked sea snake, Hydrophis schistosus: A minimalist toxin arsenal and its cross-neutralization by heterologous antivenoms. J. Proteomics 126, 121-130. https://doi.org/10.1016/j.jprot.2015.05.035

Tan, K.Y., Tan, C.H., Fung, S.Y., Tan, N.H., 2016. Neutralization of the Principal Toxins from the Venoms of Thai Naja kaouthia and Malaysian Hydrophis schistosus: Insights into ToxinSpecific Neutralization by Two Different Antivenoms. Toxins 8, 86. https://doi.org/10.3390/toxins8040086

Tan, N.H., Wong, K.Y., Tan, C.H., 2017. Venomics of Naja sputatrix, the Javan spitting cobra: A short neurotoxin-driven venom needing improved antivenom neutralization. J. Proteomics 157, 18-32. https://doi.org/10.1016/j.jprot.2017.01.018

World Health Organisation, 2010. WHO guidelines for the production, control and regulation of snake antivenom immunoglobulins. World Health Organization, Geneva. 
Chromatogram of representative venom

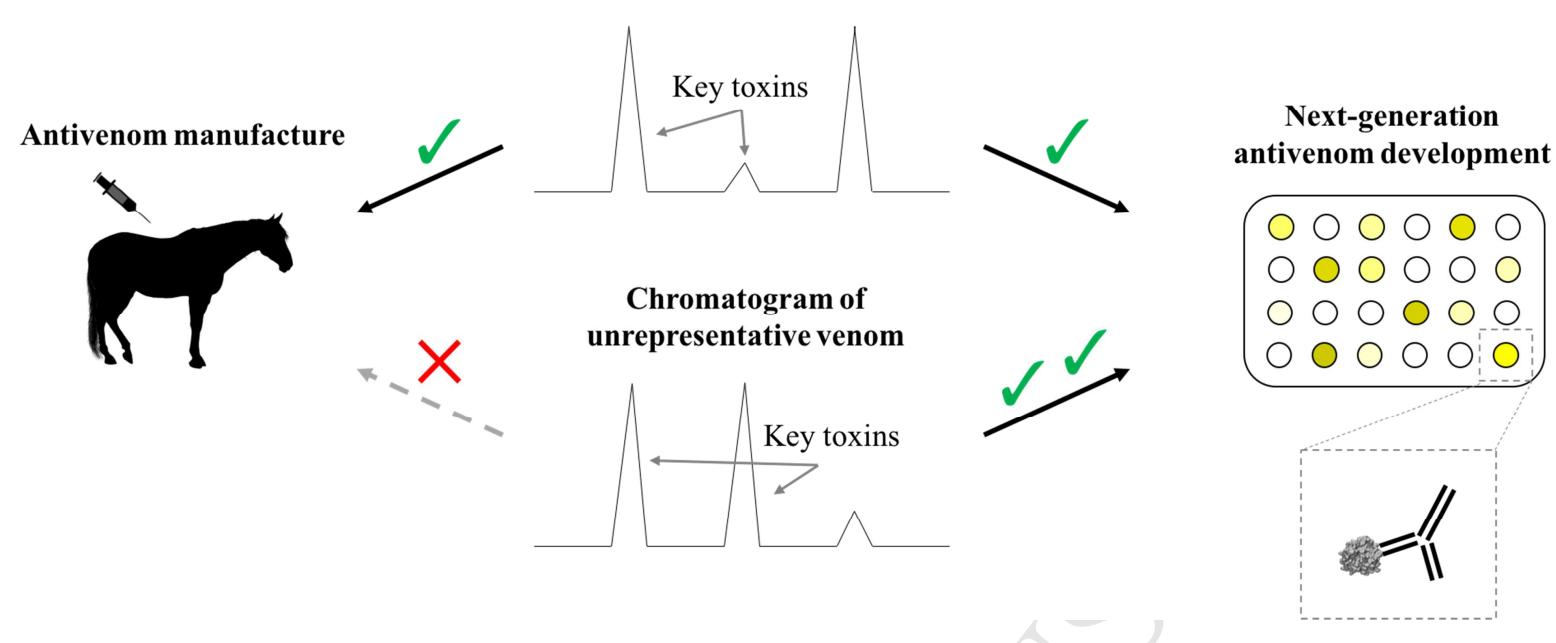




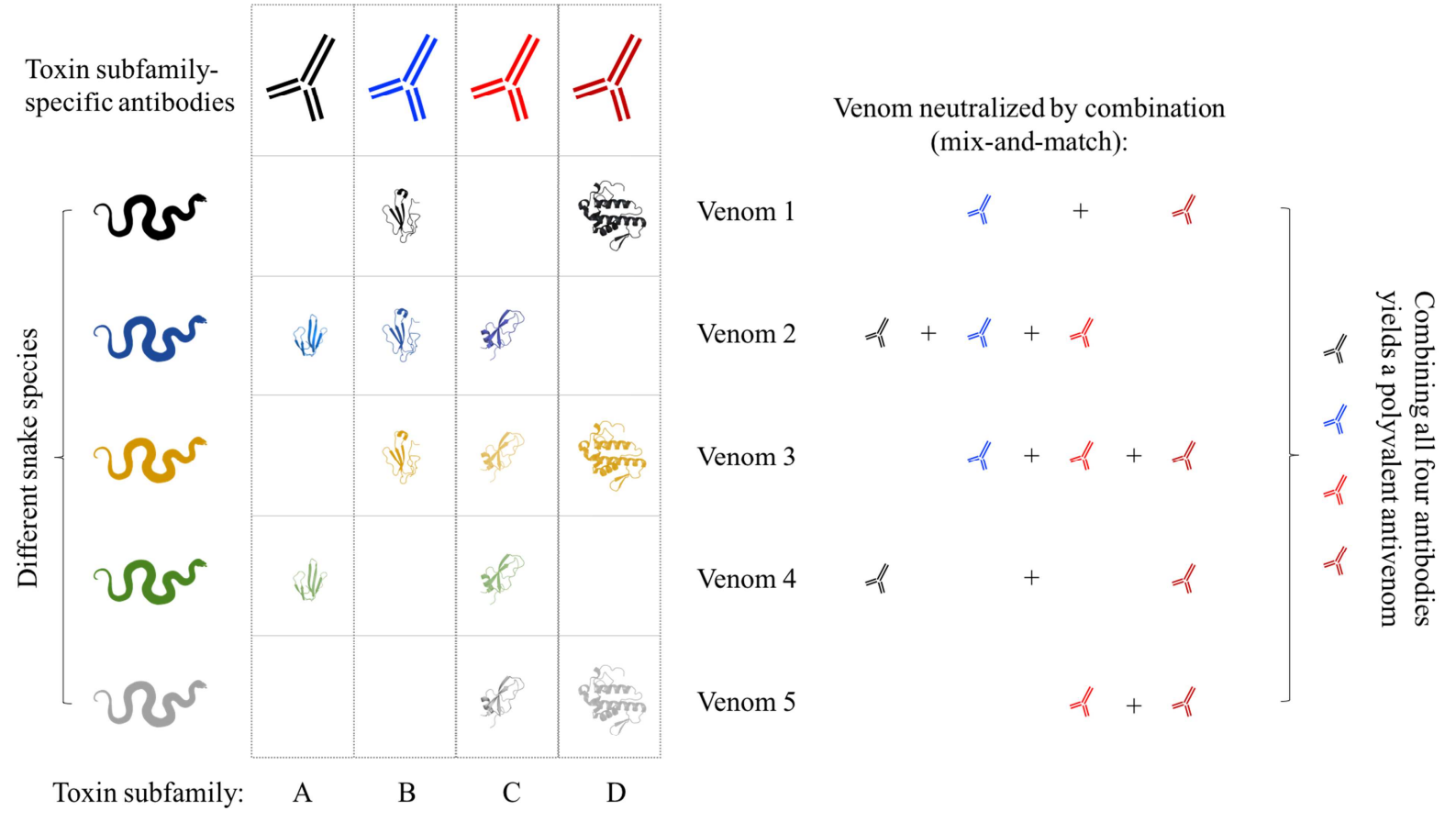


Conflicts of Interest: The author declares no conflict of interest. 